\title{
Identification of Enablers for Reducing Student Incivility in Classrooms-An Exploratory Investigation
}

\author{
Tapas Bantha ${ }^{1}$, Dr. Sanjeev P. Sahni ${ }^{2} \&$ Dr. Mohit Yadav ${ }^{3}$ \\ ${ }^{1}$ Jindal Institute of Behavioural Sciences (JIBS), O.P. Jindal Global University, Sonipat, Haryana-131001 (INDIA) \\ ${ }^{2}$ Principal Director, Jindal Institute of Behavioral Sciences (JIBS), O.P. Jindal Global University, India \\ ${ }^{3}$ Assistant Professor, Jindal Global Business School (JGBS), O.P. Jindal Global University, India \\ Correspondence: Tapas Bantha, Jindal Institute of Behavioural Sciences (JIBS), O.P. Jindal Global University, \\ Sonipat, Haryana-131001 (INDIA)
}

Received: December 17, 2019

Accepted: January 20, 2020

Online Published: January 30, 2020

doi:10.5430/ijhe.v9n2p193

URL: https://doi.org/10.5430/ijhe.v9n2p193

\begin{abstract}
There is a growing concern about student incivility in classrooms among academicians and institutional leaders. This study humbly tried to identify various enablers for reducing student incivility in classrooms through an exploratory investigation. This study uses empirical qualitative methods of investigation in a higher educational institution based at Delhi, NCR, India. The authors have conducted open-ended, unstructured interviews with 8 faculty members of various departments of the institution. This study able to develop three major themes and twelve sub themes as enablers to reduce student incivility in the classroom. The thematic map shall help the faculties and policy makers to integrate various mechanisms to control student incivility in classrooms. Incivil behaviour of the students creates disruption in the process of learning and teaching at the academic institutes. The behaviour of the particular students can be ranged from various dimensions i.e. from rudeness to lack of interest in class participation and learning process. There are various challenges used to be faced by teaching professionals in higher education with respect to student incivility (Bjorklund and Rehling, 2009; Clark, 2008). The misconduct inclined with disrespect hurts the true spirit of the learning classroom (Swinney, Elder and Seaton, 2010). The primary purpose of this paper to identify various enablers/mechanisms which can reduce student incivility in classrooms at higher education context, which will be itself a significant contribution for the practical implications that will be very much useful for the faculties and administrators of higher education institutes.
\end{abstract}

Keywords: student incivility, academicians, institutional leaders, qualitative

\section{Introduction}

\subsection{Overview}

According to Merriam-Webster, incivility can be defined as "rude or discourteous act" (Definition of incivility, n.d.). Incivility is not an alien term in educational context but it creates enormous pressure on the faculties and for the educational community as a whole. The solidity and alliance among the faculty members at stake due to threatening environment at classroom due to the incivility. Apart from the environment there is emotional turbulence and other conflict inducing factors which gravitates the classroom situation and makes it more perplexing. There are various key words used to describe incivility in a classroom i.e. "misconduct", "impoliteness", "disruptive behaviour" "rudeness" etc. Incivility can be incurred at any space during the process of teaching and learning and because of that there is withdrawal cognitions, lack of attention and concentration among students (Longobardi, Prino, Marengo and Settanni, 2016; Penconek, 2014).

\subsection{Research Questions}

What are the various enablers which can be used to reduce student incivility in classrooms?

\subsection{Operational Definitions}

Student incivility behaviours can be defined as "discourteous or disruptive verbal and nonverbal student behaviors enacted toward others" (Morrissette, 2001). 


\subsection{Importance of the Study}

Despite there are prevalence issues of student incivility in classrooms, hardly some studies focused on the enablers/mechanisms to reduce student incivility in classrooms (Kaseem and Mohammed, 2019). This paper focuses on student classroom incivility as an important issue of concern which affect the population i.e. faculty and student community as a whole. The challenge is before the faculty community to develop a fostering environment which can enhance the learning process (Vuolo, 2018).

\section{Student Incivility-Conceptual Dimension}

There is always a incivil side of classroom which became part and parcel of higher education system (Holton, 1995). There is a continuous inclination towards incivil behaviour in higher education institutions, as the construct and the related behaviours were used to be identified by the faculties and academicians (Levine and Cureton, 1998). Incivility also has its own stake in workplaces which is termed as "workplace incivility" which is defined as "behaviors [that] are characteristically rude and discourteous, displaying a lack of regard for others" (Anderson and Pearson, 1999). Differences in learning is not only the criteria as the construct itself has got multidimensional notions, so sometimes it is very tough to generalize the notion of incivility in the context of faculties and academicians. Instructional settings and institutional context are very much different to each other in the context of incivility behaviours with reference to students, administrators and academicians (Swinney et al. 2010). There are various dimensions of incivility captured by scholars i.e. "packing up early before class is over, use of a phone to talk or text, entering late/leaving early, and talking to others" (Clark and Pamela, 2007).

\section{Causes of Student Incivility}

Situational Factors: The uncivil behaviour patterns is most of the times ignored in the perspective of retaining the students for increasing the admission standards, which is used to be taken care of the institute administrators that causes serious issues in the context of behaviour (Nordstrom, Lynn and Jayne, 2009). When the faculty members were ignored and not supported by the department and the institute administration, then most of the cases the faculty staff of the particular institute ignore the uncivil behaviour of the students. Bullying is also treated as uncivil behaviour in most of the contexts. It has got a widespread effect which is led from the cultural backgrounds of the student community (Hirschy and Braxton, 2004). Incompetence and unsuitability are also the issues associated with student incivility, where most of the faculties less report regarding it due to their performance appraisal and feedback process (Morrissette, 2001). Incivility is not at all tolerable behaviour from the dimension of academicians, but taken as acceptable by the student community. Student communities have the feeling of curtailing attitude towards the professors who usually involved in minimizing the uncivil behaviours in the classrooms which creates disruption in the environment too (Bjorklund and Rehling, 2009). There are also various dimensions like "disrespectful disruption" and "insolent inattention" which has got adverse impact on student's commitment and development (Hirschy and Braxton, 2004). Some of the uncivil behaviours were not identified which may affect the retention, that has been mostly thought by the academicians (Kuhlenschmidt and Layne, 1999). After the exams there is a subsequent evidence of students who displayed uncivil behaviours (Boice, 1996).

Psychological Factors: To overcome stress of various kinds, students develop substance towards alcohol and drugs which leads to uncivil behaviours. These sort of substances can be for coping, resisting or enjoying dimensions (Amada,1997; Kuhlenschmidt and Layne, 1999). These are the root causes for student incivility.

Technology Inclination: Most of the students now-a-days are addicted to mobiles, e-mail and other apps which is termed as "digital natives" or "Net Generation" (Hershatter and Epstein, 2010). Multi-tasking is a key term for youngsters which used to drive them to various other ways to communicate among the peers which usually crosses the scope of professional interactions. Using FB, What's-app, is common for them in the class, as they feel it is the way of communication (Hernandez and Fister, 2001). There is high technology dependent behaviours among students who knowingly use their laptops for internet during the class, which causes uncivil behaviours among the classmates that disrupts the learning environment in the class (McKinne and Martin, 2010; Rowland and Kanokraj, 2009). Students' unrealistic and immediate reactions also cause uncivil behaviours in the class (TechTrends, 2008).

Narcissism: Most of the students have self-centered attitude and only concerned about their own happiness and welfare, this is the most important force that drives the student to behave in an uncourteous manner which leads to narcissism (Westerman, Bergman, Bergman and Daly; 2012). Prevalence of disruptive behaviours usually displayed among the students who feel themselves superior among the other peers. There are also studies which validates the retaliation motive and prevalence of incivility behaviours is more in students who are having high narcissism (Nordstrom et al. 2009). 
Consumerism: Most of the students feel the teachers as their service providers and they take themselves as consumers, as they pay the fees (Nordstrom et al. 2009). Students expect the teachers should provide them all the entitled service and support as they perceive themselves right in all conditions and contexts (Baker, Comer and Martinak, 2008; Nordstrom et al. 2009).

Attitudinal Ruptures: Most of the parents enable their children to take immediate action by using the electronic gadgets, money, power etc. which causes incivility among the students (Knepp, 2012). Attitudinal inappropriateness is also a vital motivator for student incivility in the classroom (Alberts, Hazen and Theobald; 2010).

\section{Method}

In order to explore the enablers for reducing student incivility in classrooms, the researcher has adopted an informal unstructured interview method for recording the verbatim of 8 academic professionals from diversified fields and experiences. The sample included 7 assistant professors and 1 senior professor of a higher educational institution based at Delhi, NCR, of India. A request letter for appointment reg. the unstructured and informal interviews had been mailed to the concerned faculties (For details see Table-1) and the sample is a convenient one. Coding and thematic analysis has been done to explore various themes for development of various enablers to reduce student incivility in classrooms.

All the interviews had been recorded using Vivo-V7 Plus Mobile. Vivo-V7 Plus has in-built voice recorder and other features for enhancement of audio quality. The duration of interviews was varied from respondent to respondent, though some of the respondents initially agreed for 20 minutes of time but due to some unknown reasons they reduced the time significantly (for more details see Table 2).

Table 1. Details of the Respondents

\begin{tabular}{ccc}
\hline Sl. No. & Profession & Total (N) \\
\hline 1 & Assistant Professor(s) & 07 \\
2 & Senior Professor & 01 \\
Total & & 08 \\
\hline
\end{tabular}

Table 2. Duration of the Interview

\begin{tabular}{ccc}
\hline Respondent (in No) & Profession & Time (in minutes) \\
\hline 1 & Assistant Professor & 18.02 \\
2 & Assistant Professor & 04.51 \\
3 & Assistant Professor & 02.20 \\
4 & Assistant Professor & 03.49 \\
5 & Senior Professor & 27.43 \\
6 & Assistant Professor & 07.16 \\
7 & Assistant Professor & 10.04 \\
8 & Assistant Professor & 07.18 \\
Total Time (in minutes) & & 80.03 \\
Average Time/Respondent (in & & 10 \\
Minutes) & & \\
\hline
\end{tabular}

\section{Result}

Each of the audio file has been played through VLC Media Player through editing the playback speed in the playback option (slower fine/slower) which reduces the speed and helped the researcher to prepare the verbatim. For short pauses (..) used, for long pauses (.......), for cough, sneeze, smiling, laugh it is mentioned as it is in the verbatim of its occurrence. For the coding of the verbatim two set of process had been adopted. First step is the first cycle coding. For this the author(s) used coding in two cycles. In the first cycle we divided the codes based on its description and after that we tabulated the codes (respondent wise) for analysis and development of thicker description of the codes. Then basing on the description the codes has been summarized. In the second cycle, we 
compared the descriptions and the codes of each verbatim with another verbatim for further analysis and interpretation. After that process, we used thematic analysis (Auerbach and Silverstein, 2003; Boyatzis, 1998; Smith and Osborn, 2007). To understand the very notion of beliefs, contextual understanding, constructs and varied experiences of participants, the role of themes is inevitable in qualitative studies. The themes not only provide us a thicker description of the events that has happened but also explore it from the respondent's view point, rather than from the researcher's view point. To develop summary and synthesis for theming the data has got various approaches and alternatives out of which most of the researchers focus on the strategic approach, as it links various perspectives that integrates both the objective and outcome of the data that had been analyzed (Sandelowski and Barroso, 2007). Initially the verbatim has been coded. For each verbatim, there are some set of codes have been developed. Then the codes of each verbatim has been compared with other verbatim codes to find out the common codes. Common codes are those codes, which has been repeated number of times in the verbatim. For deriving themes from the common codes, thematic analysis has been adopted. During this thematic analysis, codes has been examined through established literature and out of that themes has been developed. While exploring, most of the respondents shared their views about the other dimensions of enablers for reducing student incivility in classrooms, that intrigued the researcher for further exploration. Basing on that, subsequent part of the verbatim has been explored for development of themes. After the exploration, a comparative analysis of the verbatim has been conducted to eliminate repetition of the themes. For instance, engagement, pedagogy, mutual relationship, evaluation criteria, norms and rules fixation are some of the themes which has been repeated number of times by the respondents. From the comparative analysis, thematic map has been emerged (for details see Figure 1).

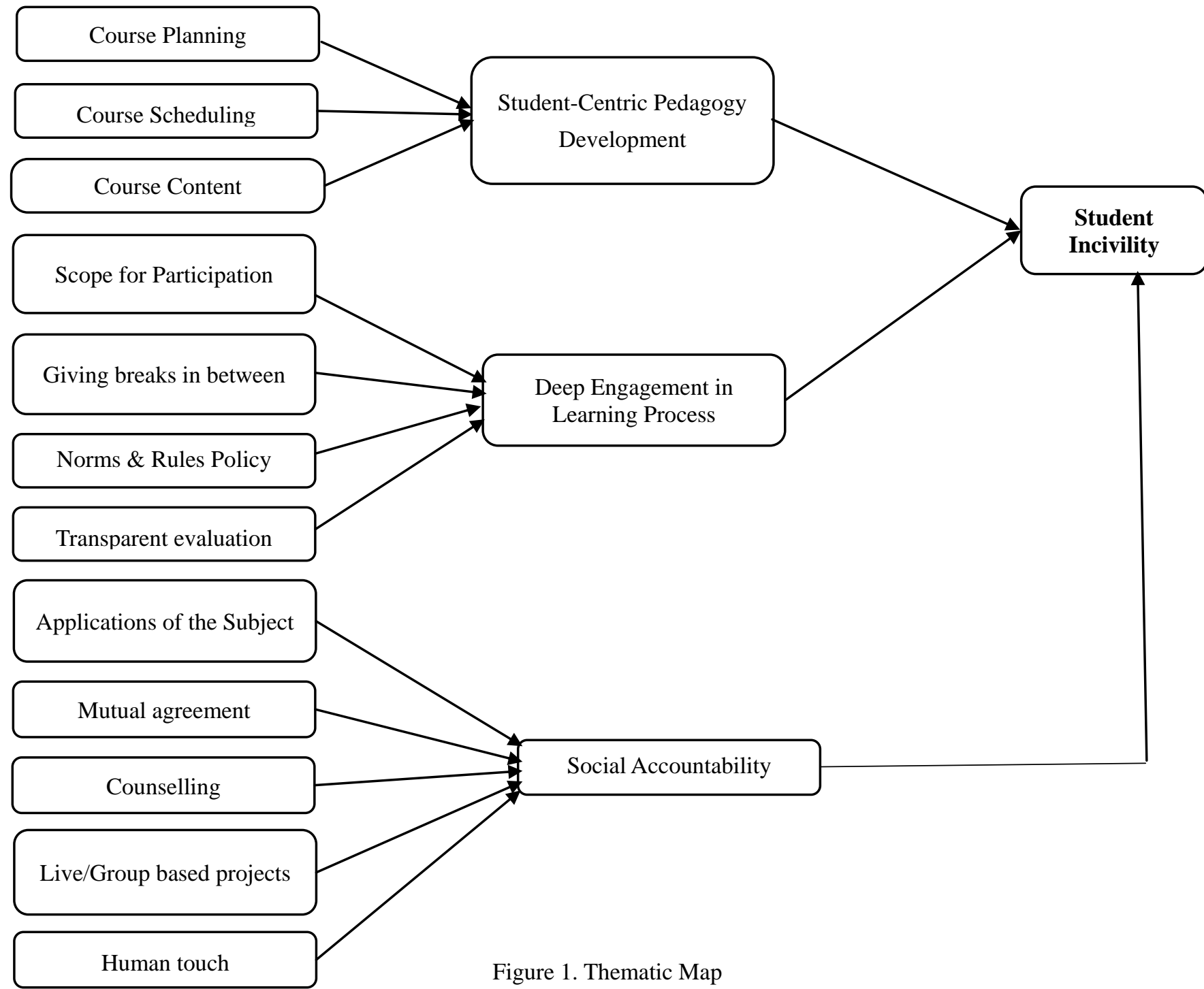


As shown in Figure.1, Thematic analysis helped in confirming the constructs identified through literature review. During the thematic analysis, different enablers were emerged which can be used to reduce student incivility in classroom at various levels. The different enablers are can be also treated as new themes which can work as enablers those were as follows: course planning, course scheduling, course content, scope for participation, giving breaks in between, norms and rules policy, transparent evaluation, applications of the subject, mutual agreement, counselling, live/group based projects, human touch which can result in student-centric pedagogy development, deep engagement in learning process and social accountability among the teachers and students which can act as enablers to reduce student's incivility behaviours in the classroom.

\section{Discussion}

Understanding incivility from the notion of academic professionals itself a unique contribution in this paper along with that the paper also discovers various themes for conceptual and empirical inquiry, that enhances credibility of the paper. The concept analysis adds to the body of knowledge on student incivility behaviour. However, it has some limitations. Firstly, due to informal interviews in an average 10 minutes is very less time for exploration of any given concept. Second limitation is the respondents profile, who are professionals in their field, getting appointment from those professionals is a herculean task. Incivility has multifaceted designs. The operationalization and conceptualization of incivility need to be explored by the scholars. Future operational enablers for reducing student incivility in the classrooms can be chosen from the eleven themes developed in this paper. Researchers should also explore various dimensions of incivility that can be integrated in employee and organizational life. This sort of paper provides a platform for researchers to develop various insights as this paper based on real-life cases. The propositions which has been developed in this paper can be further explored and empirically investigated, which may provide different insights to the academicians and policy makers.

This research has several contributions which would add to the existing body of knowledge. Firstly, this study explores various enablers which can reduce student incivility behaviours in classrooms. It also develops various propositions along with the thematic map that can be empirically investigated further. Additionally, this study attempts to link course planning, course scheduling, course content, scope for participation, giving breaks in between, norms and rules policy, transparent evaluation, applications of the subject, mutual agreement, counselling, live/group based projects, human touch which can result in student-centric pedagogy development, deep engagement in learning process and social accountability which will be an important extension of existing literature on higher education.

The research offers valuable insights to academicians, institutional leaders by providing various enablers which can be used to reduce student incivility behaviours in the classroom level and developing the students as good citizens of the country and nurturing the young brains with the true spirit of innovation and ideas. As a result, teachers would be able to develop and maintain healthy and cordial relationship with the students which can result in reducing uncivil behaviours, burn outs, counterproductive work behaviour, attrition rates at the classroom context.

\section{Conclusion}

There is a shift of paradigm in academics with respect to admission of students, substantial pressure to get degrees for employment in the part of students, these sort of pressures cause emotional turbulence in students. Faculties should be vigilant and should try to incorporate themselves with these changing trends as it will have its consequences on the classroom setting. Incivility inside the classroom should not be taken as negative always, as there may be various instances which may induce negativity among the students i.e. impervious expression towards an unfamiliar topic or a student may not be able to give complete attention in the class or in the speaker, it doesn't mean that the student is incivil, the present state of the mind of the student may affect his behaviour to behave him/her accordingly. The role of students and faculties should be understood at its core level. Various skills like empathy, sympathy, communication skills are inevitable in the side of faculty fraternity to understand the behaviour pattern of the students who used to undergo diverse experiences. There are various key aspects which should be considered by the faculty fraternity i.e. providing a platform to students for expression of their thoughts without any judgement and creating a platform for intellectual stimulating discussion. Having awareness about various areas/domains will be also an added advantage. Experiential learning should be given more priority to engage students, where the students will have a very less scope to display incivil behaviours at the classroom.

Faculties' self-reflection and participative teaching style plays a key role in contributing the classroom environment positively. Having an interpersonal communication will be an added advantage in fostering the classroom environment. Situations and contexts cannot be pre-determined, knowing this in advance, faculties should be well-aware of their dealings with students and sometimes, it can be shared with their co-workers. In case of any serious issues like "threats" "assaults", it should be represented before the administrators and security personnel. 
Faculties should try to resolve students' issues as early as possible otherwise it becomes the source of discontentment among students which can lead to faculty disengagement and job dissatisfaction.

Incivility in the classroom should be acknowledged as a root problem by the academicians and policy makers which should be dealt with pioneering measures, this is a need of the hour.

\section{References}

Alberts HC, Hazen HD, \& Theobald RB. (2010). Classroom Incivilities: The Challenge of Interactions between College Students and Instructors in the US. Journal of Geography in Higher Education, 34(3), 439-62. https://doi.org/10.1080/03098260903502679

Amada G. (1997). The Disruptive College Student. Journal of College Student Psychotherapy, 11(4),57-67. https://doi.org/10.1300/j035v11n04_05

Andersson LM, \& Pearson CM. (1999). Tit for Tat? The Spiraling Effect of Incivility in the Workplace. The Academy of Management Review, 24(3),452. https://doi.org/10.2307/259136

Auerbach CF, \& Silverstein LB. (2003). Qualitative data: an introduction to coding and analysis. New York: New York University Press, 202 p. (Qualitative studies in psychology).

Baker SD, Comer DR, \& Martinak ML. (2008). All I'm askin is for a little respect: How can we promote civility in our classrooms? Organization Management Journal, 5(2), 65-80. https://doi.org/10.1057/omj.2008.8

Bjorklund WL, \& Rehling DL. (2009). Student Perceptions of Classroom Incivility. College Teaching, 58(1), 15-8. https://doi.org/10.1080/87567550903252801

Boice B. (1996). Classroom incivilities. Res High Educ, 37(4), 453-86. https://doi.org/10.1007/BF01730110

Boyatzis RE. (1998). Transforming qualitative information: thematic analysis and code development. Thousand Oaks, CA: Sage Publications, 184 p.

Clark CM. (2008). Faculty and Student Assessment of and Experience with Incivility in Nursing Education. J Nurs Educ, 47(10), 458-65. https://doi.org/10.3928/01484834-20081001-03

Clark Cynthia M, \& Pamela J. (2008). Thoughts on incivility: Student and faculty perceptions of uncivil behaviour in nursing education. Nursing Education Perspectives, 28(2), 93-97.

Definition of incivility [Internet]. [cited 2019 Dec 17]. Available from: https://www.merriam-webster.com/dictionary/incivility

Good Intentions and Unanticipated Effects: The Unintended Consequences of the Application of Technology in Teaching and Learning Environments. (2008). TECHTRENDS TECH TRENDS, 52(5), 52-8. https://doi.org/10.1007/s11528-008-0197-y

Hernández TJ, \& Fister DL. (2001). Dealing With Disruptive and Emotional College Students: A Systems Model. Journal of College Counseling, 4(1), 49-62. https://doi.org/10.1002/j.2161-1882.2001.tb00182.x

Hershatter A, \& Epstein M. (2010). Millennials and the World of Work: An Organization and Management Perspective. Journal of Business Psychology, 25(2), 211-23. https://doi.org/10.1007/s10869-010-9160-y

Hirschy AS, \& Braxton JM. (2004). Effects of student classroom incivilities on students. New Directions for Teaching and Learning, 2004(99), 67-76. https://doi.org/10.1002/tl.160

Holton SA. (1995). Conflict management in higher education. San Francisco: Jossey-Bass.

Kassem AH, \& Mohammed BA. (2019). Incivility Behavior and Engagement among Technical and Health Institute Nursing Students at the Classroom. International journal of Nursing Didactics, 9(05), 19-28. https://doi.org/10.15520/ijnd.v9i05.2578

Knepp Frey A. (2012). Understanding student and faculty incivility in Higher Education. Journal of Effective Teaching, 12(1), 33-46.

Kuhlenschmidt SL, \& Layne LE. (1999). Strategies for Dealing with Difficult Behavior. New Directions for Teaching and Learning, 1999(77), 45-57. https://doi.org/10.1002/tl.7705

Levine A, \& Cureton JS. (1998). What We Know: About Today's College Students. About Campus, 3(1), 4-9. https://doi.org/10.1177/108648229800300103

Longobardi C, Prino LE, Marengo D, \& Settanni M. (2016). Student Teacher Relationships As a Protective Factor 
for School Adjustment during the Transition from Middle to High School. Frontiers in Psychology, 7, 1-9. https://doi.org/10.3389/fpsyg.2016.01988

McKay R, Arnold DH, Fratzl J, \& Thomas R. (2008). Workplace Bullying In Academia: A Canadian Study. Employ Respons Rights J, 20(2), 77-100. https://doi.org/10.1007/s10672-008-9073-3

McKinne M, \& Martin BN. (2010). Higher Education Faculty and Student Perceptions of Classroom Incivility. Journal of College and Character, 11(2), 5. https://doi.org/10.2202/1940-1639.1249

Morrissette Patrick J. (2001). Reducing incivility in the university/college classroom. International electronic journal for leadership and learning, 5(4), 5.

Nordstrom Cynthia R, Lynn K. Bartels, \& Jayne Bucy. (2009). Predicting and curbing classroom incivility in higher education. College Student Journal, 43(1), 74-86.

Penconek T. (2014). Beware of Uncharitable Speech: Perceptions of Newly Graduated Nurses regarding their Experiences of Academic Incivility between and among Nursing Students in Undergraduate Nursing Education [Internet]. 2014 [cited 2020 Jan 6]. Available from: https://dt.athabascau.ca/jspui/handle/10791/55

Rowland M, \& Kanokraj S. (2009). Dental students' and faculty members' perceptions of incivility in the classroom. Journal of Dental Education, 73(1), 119-126.

Sandelowski M, \& Barroso J. (2007). Handbook for synthesizing qualitative research. New York: Springer Publishing Company, $284 \mathrm{p}$.

Smith JA, \& Osborn M. (2007). Pain as an assault on the self: An interpretative phenomenological analysis of the psychological impact of chronic benign low back pain. Psychology and health, 22(5), 517-534. https://doi.org/10.1080/14768320600941756

Swinney L, Elder B, \& Seaton L 'Pat'. (2010). Incivility in The Accounting Classroom. AJBE [Internet]. 2010 Dec 15 [cited 2019 Dec 17], 3(5). https://doi.org/10.19030/ajbe.v3i5.422

Vuolo J. (2018). Student nurses' experiences of incivility and the impact on learning and emotional wellbeing. 2018 Apr 1 [cited 2020 Jan 6]; Available from: http://uhra.herts.ac.uk/handle/2299/20652

Westerman JW, Bergman JZ, Bergman SM, \& Daly JP. (2012). Are Universities Creating Millennial Narcissistic Employees? An Empirical Examination of Narcissism in Business Students and Its Implications. Journal of Management Education, 36(1), 5-32. https://doi.org/10.1177/10525629114080907 